\title{
Study Subject MRI Report
}

National Cancer Institute

\section{Source}

National Cancer Institute. Study Subject MRI Report. NCI Thesaurus. Code C115512.

Reports pertaining to the findings from a study subject's magnetic resonance imaging results. 